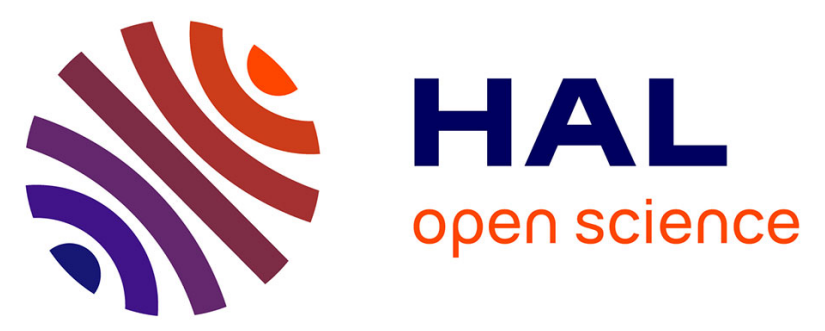

\title{
Association of non-HDL cholesterol with subclinical atherosclerosis in HIV-positive patients.
}

Stéphanie Badiou, Rodolphe Thiébaut, Valérie Aurillac-Lavignolle, Francois

Dabis, Frédéric Laporte, Jean-Paul Cristol, Patrick Mercié, Groupe

d'Epidémiologie Clinique Du Sida En Aquitaine (gesca)

\section{To cite this version:}

Stéphanie Badiou, Rodolphe Thiébaut, Valérie Aurillac-Lavignolle, Francois Dabis, Frédéric Laporte, et al.. Association of non-HDL cholesterol with subclinical atherosclerosis in HIV-positive patients.: Non-HDL cholesterol and atherosclerosis in HIV patients.. Journal of Infection, 2008, 57 (1), pp.47-54. 10.1016/j.jinf.2008.05.007 . inserm-00280760

\section{HAL Id: inserm-00280760 https://www.hal.inserm.fr/inserm-00280760}

Submitted on 19 Jun 2008

HAL is a multi-disciplinary open access archive for the deposit and dissemination of scientific research documents, whether they are published or not. The documents may come from teaching and research institutions in France or abroad, or from public or private research centers.
L'archive ouverte pluridisciplinaire HAL, est destinée au dépôt et à la diffusion de documents scientifiques de niveau recherche, publiés ou non, émanant des établissements d'enseignement et de recherche français ou étrangers, des laboratoires publics ou privés. 
Elsevier Editorial System(tm) for Journal of Infection

Manuscript Draft

Manuscript Number: YJINF-D-08-00122R1

Title: ASSOCIATION OF NON-HDL CHOLESTEROL WITH SUBCLINICAL ATHEROSCLEROSIS IN HIVPOSITIVE PATIENTS

Article Type: Full Length Article

Section/Category: Rest of the World Submissions

Keywords: apolipoprotein B; atherosclerosis; HIV infection; intima-media thickness; metabolic syndrome; non-HDL-cholesterol; TG/HDL ratio.

Corresponding Author: Dr Stephanie Badiou,

Corresponding Author's Institution: University Hospital of Montpellier

First Author: Stephanie Badiou

Order of Authors: Stephanie Badiou; Rodolphe Thiebaut; Valerie Aurillac-Lavignolle; François Dabis;

Frederic Laporte; Jean-Paul Cristol; Patrick Mercie

Manuscript Region of Origin:

Abstract: Objectives: To assess the relationship between non classical cardiovascular (CV) risk factors including non-HDL cholesterol (non-HDL-C), apolipoprotein B, Triglycerides to HDL ratio, LDL size, inflammation or oxidative stress parameters and carotid intima-media thickness (CIMT), in order to better identify prevention or therapeutic targets. In addition, we studied the relationship between metabolic syndrome (MS) and CIMT.

Methods: Cross-sectional study including 232 HIV-positive (HIV+) adults ( $80 \%$ treated by combined antiretroviral therapy) extracted from the ANRS $\mathrm{CO} 3$ Aquitaine Cohort.

Results: There was a significant association of higher non-HDL-C $(p<0.01)$, apolipoprotein $B(p<0.01)$ levels or TG/HDL ratio $(p<0.05)$ with higher CIMT when compared the first versus fourth quartile, while there is no association between CIMT and LDL-C $(p=0.09)$ or LDL size $(p=0.55)$. In multivariate analysis, only the 
TG/HDL molar ratio $>1.5$ tend toward significance $(p=0.08)$. MS was observed in only $7.3 \%$ of patients with the NCEP-ATPIII definition and $11.2 \%$ with the IDF criteria. Whatever the used definition, there was a significant association between MS presence and increased CIMT $(p<0.05)$ in univariate and multivariate model.

Conclusions: Non-HDL-C, TG/HDL ratio and apolipoprotein B levels, which are closely linked to lipid disorders associated to the MS, appear as stronger predictive markers than LDL-C for screening sub-clinical atherosclerosis in HIV+ populations. Achieving non-HDL-C target defined by the NCEP-ATPIII guidelines appears of great importance to reduce CV complications in HIV+ patients. 
Montpellier, $16^{\text {th }}$ May 2008

Dear Professor,

Thank you very much for reviewing our manuscript numbered YJINF-D-08-00122 and for allowing us to submit our revision with an additional week. We found the reviewer's comments very interesting and we have revised our manuscript according point by point to all their helpful comments. In this way, the Title was modified as: "Association of non-HDL cholesterol with subclinical atherosclerosis in HIV-positive patients".A detailed response for each referee was presented in the file named "Response".

We hope that this manuscript is now suitable for publication in "Journal of Infection" and we would like to take this opportunity to thank the independent referees for their help to improve the quality of this article.

Sincerely yours

Dr S Badiou 


\section{$\underline{\text { Response to the Editors and reviewers }}$}

We are very grateful to the Editors and reviewers to their helpful comments to improve our manuscript.

\section{Reply to observations of reviewer 1}

First and all, we take the opportunity to thank the anonymous referee for his interesting comments.

1. In order to improve the statistical analysis we added a multivariate analysis including age, gender and tobacco consumption. Adjusted p-values were added in the Tables 1 and 2.

The Statistics section was modified as follows:

"Comparisons of CIMT values according to marker levels were done using a Student t-test and ANOVA when appropriate. Adjustment on age, gender and tobacco consumption was performed with a multiple linear regression." (page 7)

The Results section was modified as follows:

Increased TC, non-HDL-C, apoB levels and TG/HDL ratio were significantly associated with a $0.05 \mathrm{~mm}$ increase in CIMT when comparing the highest quartile against the lowest one in univariate analysis (Table 1). After adjustment on age, gender and tobacco consumption, these relationships disappeared but it remained a trend toward significant association between TG/HDL $>1.5$ and CIMT $(p=0.08)$. ....

Interestingly, LDL-C recognized in the general population as the most common lipid risk factor, was not significantly associated with CIMT $(p=0.09)$ in univariate analysis by contrast to non-HDL-C levels. (page 8)

The Discussion section was also modified accordingly to these new data as follows:

In this study, we demonstrated that non-HDL-C, apoB or TG/HDL ratio are stronger predictive factors of increased CIMT than LDL-C in HIV+ patients, in univariate analysis, while after adjustment on age, sex and smoking habits, TG/HDL ratio $>1.5$ appeared as an interesting determinant of sub-clinical atherosclerosis. 
Although an increase in non-HDL-C was statistically associated to increased CIMT in univariate analysis only (Table 1), it appears necessary to reach the non-HDL$\mathrm{C}$ goal after the LDL-C goal in HIV+ patients who are generally exposed to multiple CV risks and predisposed to increased atherosclerosis ${ }^{6,8-10,12}$. A particularity of dyslipidemia in HIV+ patients treated by c-ART is the combination of lipid disturbances related firstly to the HIV infection per se and secondly induced by c-ART. Management of this complex dyslipidemia appears as an important challenge for clinicians, as often, lipid lowering therapy alone does not allow to reach the lipid $\operatorname{target}^{36,41,42}$ and should be associated to diet and lifestyle modification and/or switching of some antiretroviral agents $^{43}$. A specific disturbance that persists in about half of patients is the trend to low HDL-C levels and moderate hypertriglyceridemia. In this context, the determination of a TG/HDL cut-off associated to a significant subclinical atherosclerosis presence appears as a useful tool for clinicians. The TG/HDL molar ratio was previously reported as a marker of LDL size with a cut-off at 1.3 for identifying diabetic patients having small dense $\mathrm{LDL}^{44}$. In addition to a significant linear correlation between TG/HDL ratio and LDL size $\left(r=-0.36 \mathrm{p}^{-4} \mathbf{1 0}^{-4}\right)$ observed in our study, a value of 1.5 was identified as the significant cut-off for distinguishing HIV+ patients having higher CIMT. Furthermore, other studies such as the DAD collaboration reported an independent effect of dyslipidemia on myocardial infarction in $\mathrm{HIV}+$ patients underlining the need to analyse more deeply those lipid abnormalities ${ }^{45}$. (page 12)

2. As requested, we mentioned in the Discussion the limitation of IMT measurement and added a reference that compares common and internal CIMT (ref $n^{\circ} 49$. Mangili A et al. Clin Infect Dis 2007;44:1368-74):

"The statistical significant association between the MS presence and increase in the CIMT was similar whatever the definition used, in univariate and multivariate analysis (Table 2). This observation was in agreement with recent data reporting a significant association between increased common CIMT and MS presence, while internal CIMT was similar in patients with and without $\mathrm{MS}^{49}$, a result that could be due in part to the lesser variability of common CIMT measurement. In our study, CIMT was measured only on the left far wall carotid arterial in order to obtain more interpretable findings for all patients, but the bulb or the internal carotid was not explored." (page 13) 
Reply to observations of reviewer 2

First and all, we take the opportunity to thank the reviewer for his helpful comments to improve our manuscript.

1. As suggested by the referee, we modified the title as "Association of non-HDL cholesterol with sub-clinical atherosclerosis in HIV-positive patients." in order to have less emphasis on CIMT and to mention the non-HDL cholesterol.

2. In agreement with the referee comments, we added in the Discussion two recent publications as follows:

The statistical significant association between the MS presence and increase in the CIMT was similar whatever the definition used, in univariate and multivariate analysis (Table 2). This observation was in agreement with recent data reporting a significant association between increased common CIMT and MS presence, while internal CIMT was similar in patients with and without $\mathrm{MS}^{49}$, a result that could be due in part to the lesser variability of common CIMT measurement. In our study, CIMT was measured only on the left far wall carotid arterial in order to obtain more interpretable findings for all patients, but the bulb or the internal carotid was not explored. Controversial results were reported in HIV+ women, as no difference of CIMT was observed between patients with and without $\mathrm{MS}^{50}$. In our, study patients with MS were more likely to have lipodystophy compared to those without MS (58.8\% vs $35.8 \%$ and $69.2 \%$ vs $33.5 \%$ with NCEP-ATPIII and IDF definition, respectively), in line with the overlap of some abnormalities of lipodystophy such as visceral lipo-accumulation or insulin resistance with components of the MS diagnosis. However, the low rate of MS could hide some association as there was no difference in frequency of PI use between patients with or without MS $(52.9 \%$ vs $48.8 \%$ and $46.1 \%$ vs $49.5 \%$ with NCEP-ATPIII and IDF definition, respectively) by contrast to the relationship between PI exposure and MS previously reported in larger cohort ${ }^{51}$, or in a women only cohort ${ }^{50}$. Nevertheless, the relative under-representation of MS in our rather young HIV+ cohort (41 \pm 9 years) compared to previous reports ${ }^{51-53}$ was in agreement with epidemiological data obtained in a large French cohort, mostly HIV-negative, reporting MS (NCEP-ATP III criteria) in $\mathbf{1 0 . 2} \%$ of men with a mean age of 48 years, dropping to $5 \%$ for subjects younger than 40 years $^{54}$. (page 13) 
49. Mangili A et al. Clin Infect Dis 2007;44:1368-74.

50. Johnsen S et al. J Clin Endocrinol Metab 2006;91:4916-24

\section{Introduction section :}

- The first three sentences were modified according to the reviewer's request as follows:

"The introduction of combined antiretroviral therapy (c-ART) has significantly increased the survival rates of HIV-positive $(\mathbf{H I V}+)$ patients and has improved their quality of life ${ }^{1}$. However emergence of cardiovascular $(\mathrm{CV})$ complications related to HIV infection per se and/or to c-ART has raised clinical and public health concerns ${ }^{2-5}$ given the increasing duration of exposure to c-ART. Several classical CV risk factors including age, gender, body mass index (BMI), blood pressure, increased total cholesterol (TC) levels or tobacco consumption have been previously recognized in HIV+ patients ${ }^{6}$. Surprisingly, there are contradictory reports on the association between low density lipoprotein cholesterol (LDL-C), the most recognized lipid risk factor in non-HIV populations ${ }^{7}$, and CIMT in HIV+ populations $\mathrm{s}^{8-11}$.

7. Eisenberg DA et al Am J Med 1998.

- The reference corresponding to the LT definition was added in the sentence 7. 16. Austin et al Circulation 1990; 82:495-506.

\section{Patients and Methods section:}

- Supra and ANRS CO3 were spelled out : "This ancillary study was performed on $232 \mathrm{HIV}+$ patients from the SUPRA (Surveillance of the Progression of Atherosclerosis) study sample extracted from the ANRS CO3 (Agence Nationale de Recherches sur le SIDA et les hépatites virales) Aquitaine cohort."

- The second sentence was modified as follows: "In brief, $423 \mathrm{HIV}+$ patients were included consecutively between September and December 1999 in order to investigate the extent of atherosclerosis by measuring the CIMT and studying CV risk factors ${ }^{8 "}$

- The fourth sentence was corrected by changing "formed" to "selected" as suggested.

- The asterix were used as indent and was now changed to appropriate indent.

- We totally agree with the referee that fibrate treatment was not mentionned in the NCEP-ATPIII definition of metabolic syndrome. We now specified the criteria of diagnosis in 
agreement with the original definition and added this sentence in the text (page 6) "In addition, patients treated by hypertensive medication were categorized as having high blood pressure, and patients receiving fibrate treatment were considered as having TG $\geq 1.5$ g/l." (page 6)

In this study, 7 patients were categorized as MS on the basis of these medications.

- In the first manuscript, no adjustment was performed, so we are now providing adjusted $\mathrm{p}$ values for age, gender and tobacco consumption. Because this multivariate model produces less statistical relationship between lipid parameters and CIMT, results and discussion section were modified in this revised manuscript.

\section{Results section :}

- There is no type setting error concerning duration of antiretroviral therapy. Perhaps, NNRTI duration is low because this is a "old" cohort recruited in 1999 and there were fewer NNRTIs available than today.

- The first sentence of the second paragraph was modified as requested to include "in the general population":

- The asterix were removed and replaced by indents.

- The second sentence of section 3 was corrected as requested by adding "compared to the absence of MS".

- The first sentence of paragraph 4 , section 3 was divided in two pieces in order to simplify the reading as follows: "Beyond hypertriglyceridemia and low HDL-C levels, patients with MS compared to those without had significant increase in non-HDL-C and apoB levels, whatever the definition used. The lipid profile of patients with the MS was also characterized by decreased apoA1 levels and LDL size when compared to patients without MS while TC and LDL-C were similar (Table 3)".

- The next sentence, was modified as suggested: "There was no difference in inflammation markers including hs-CRP, albumin and prealbumin levels according to the presence or absence of the MS (Table 3)". 


\section{Reply to observations of reviewer 3}

First and all, we take the opportunity to thank the reviewer for his helpful comments to improve our manuscript.

1. Among the entire SUPRA cohort of 423 patients, only 232 patients were selected in this sub-study on the basis of available frozen aliquots stored at $-80^{\circ} \mathrm{C}$. For all non-studied patients the restriction factor was the volume of frozen sample. Hopefully, this selection did not lead to bias as there was no significant difference between the characteristics of patients for this subgroup compared to the remaining of cohort. This was noted in the study design as follows: "A subgroup of 232 patients was selected on the basis of available aliquots frozen at $-80^{\circ} \mathrm{C}$ to perform complementary analysis including inflammation, oxidative stress parameters and LDL size determination. There was no significant difference between the characteristics of patients of this subgroup of 232 patients compared to the entire cohort of 423 patients." (page 4).

2. As underlined by the referee, LDL-C was calculated using Friedwald's formula instead of direct measurement. This formula was not applied to the nine patients with $\mathrm{TG}>4.5 \mathrm{mmol} / \mathrm{l}$, (3.9\% of 232 patients). This was stated in the discussion as follows: "Although LDL-C was determined by the use of Friedwald's formula, it is unlikely that the relationship between LDL-C and CIMT has been skewed, as there were only nine patients (3.9\%) with TG levels $\geq 4.5 \mathrm{mmol} / \mathrm{l}$, whose measurements did not allow the LDL-C calculation" (page 11).

3. We totally agree with the referee that fibrates and hypertensive medications were not specified as MS criteria in the NCEP-ATPIII definition by contrast with the WHO or the IDF definitions. So, we removed them from the criteria in the text and added the following sentence: "In addition, patients treated by hypertensive medications were categorized as having high blood pressure, and patients receiving fibrate treatment were considered as having TG>1.5 g/l". (page 6)

In this study, 7 patients were defined as having a MS on the basis of an hypertensive/or fibrate treatment. 
4. The cohort was enrolled between 1999 and 2001, perhaps explaining the low rate of duration of c-ART, especially for NNRTIs as there were fewer available than today. We confirm that there was no type setting error in the text.

5. This study was an exploratory study looking for potential determinants of the CIMT. Therefore, we did not plan to correct the alpha risk because of multiple statistical testing. Nevertheless, any correction would not modify our conclusions as the majority of p values were either clearly significant (e.g. $<0.01$ ) or non significant.

6. We agree that the presence of lipo-accumulation influences the waist perimeter and so we added a new sentence in the Discussion to mention the overlap between lipodystrophy and some metabolic syndrome components : "In our, study patients with MS were more likely to have lipodystophy compared to those without MS $(58.8 \%$ vs $35.8 \%$ and $69.2 \%$ vs $33.5 \%$ with NCEP-ATPIII and IDF definition, respectively), in line with the overlap of some abnormalities of lipodystophy such as visceral lipo-accumulation or insulin resistance with components of the MS diagnosis." (page 13) 


\begin{abstract}
Objectives: To assess the relationship between non classical cardiovascular (CV) risk factors including non-HDL cholesterol (non-HDL-C), apolipoprotein B, Triglycerides to HDL ratio, LDL size, inflammation or oxidative stress parameters and carotid intima-media thickness (CIMT), in order to better identify prevention or therapeutic targets. In addition, we studied the relationship between metabolic syndrome (MS) and CIMT.

Methods: Cross-sectional study including 232 HIV-positive (HIV+) adults $(80 \%$ treated by combined antiretroviral therapy) extracted from the ANRS CO3 Aquitaine Cohort.

Results: There was a significant association of higher non-HDL-C $(\mathrm{p}<0.01)$, apolipoprotein B $(\mathrm{p}<0.01)$ levels or TG/HDL ratio $(\mathrm{p}<0.05)$ with higher CIMT when compared the first versus fourth quartile, while there is no association between CIMT and LDL-C ( $\mathrm{p}=0.09)$ or LDL size $(\mathrm{p}=0.55)$. In multivariate analysis, only the $\mathrm{TG} / \mathrm{HDL}$ molar ratio $>1.5$ tend toward significance $(p=0.08)$. MS was observed in only $7.3 \%$ of patients with the NCEP-ATPIII definition and $11.2 \%$ with the IDF criteria. Whatever the used definition, there was a significant association between MS presence and increased CIMT $(p<0.05)$ in univariate and multivariate model.

Conclusions: Non-HDL-C, TG/HDL ratio and apolipoprotein B levels, which are closely linked to lipid disorders associated to the MS, appear as stronger predictive markers than LDL-C for screening sub-clinical atherosclerosis in HIV+ populations. Achieving non-HDL$\mathrm{C}$ target defined by the NCEP-ATPIII guidelines appears of great importance to reduce CV complications in HIV+ patients.
\end{abstract}




\section{ASSOCIATION OF NON-HDL CHOLESTEROL WITH SUBCLINICAL ATHEROSCLEROSIS IN HIV-POSITIVE PATIENTS.}

\section{Running title: Non-HDL cholesterol and atherosclerosis in HIV patients.}

Badiou $\mathrm{S}^{1}$, Thiebaut $\mathrm{R}^{2}$, Aurillac-Lavignolle $\mathrm{V}^{2}$, Dabis $\mathrm{F}^{2}$, Laporte $\mathrm{F}^{3}$, Cristol $\mathrm{JP}^{1}$, Mercie $\mathrm{P}^{2,4}$; Groupe d'Epidémiologie Clinique du Sida en Aquitaine (GECSA) ${ }^{2,5}$.

${ }^{1}$ Biochemistry department, University Hospital of Montpellier, F 34295, France

${ }^{2}$ INSERM, U593, ISPED, University of Bordeaux, F 33076, France

${ }^{3}$ Biochemistry department, University Hospital of Grenoble, F 38000, France

${ }^{4}$ Internal Medicine and Infectious Diseases, University Hospital of Bordeaux, F 33076, France

${ }^{5}$ CISIH/COREVIH, University Hospital of Bordeaux, F 33076, France

\section{Adress for correspondence}

Pr Jean-Paul Cristol

Biochemistry Laboratory, Lapeyronie University Hospital

371, Avenue Doyen Gaston Giraud

F34295 Montpellier Cedex 5, France

phone: 33467338315

Fax: 33467338393

e-mail: jp-cristol@chu-montpellier.fr 


\section{Abstract}

Objectives: To assess the relationship between non classical cardiovascular (CV) risk factors including non-HDL cholesterol (non-HDL-C), apolipoprotein B, Triglycerides to HDL ratio, LDL size, inflammation or oxidative stress parameters and carotid intima-media thickness (CIMT), in order to better identify prevention or therapeutic targets. In addition, we studied the relationship between metabolic syndrome (MS) and CIMT.

Methods: Cross-sectional study including 232 HIV-positive (HIV+) adults ( $80 \%$ treated by combined antiretroviral therapy) extracted from the ANRS CO3 Aquitaine Cohort.

Results: There was a significant association of higher non-HDL-C $(\mathrm{p}<0.01)$, apolipoprotein B $(\mathrm{p}<0.01)$ levels or TG/HDL ratio $(\mathrm{p}<0.05)$ with higher CIMT when compared the first versus fourth quartile, while there is no association between CIMT and LDL-C ( $\mathrm{p}=0.09)$ or LDL size $(\mathrm{p}=0.55)$. In multivariate analysis, only the $\mathrm{TG} / \mathrm{HDL}$ molar ratio $>1.5$ tend toward significance $(\mathrm{p}=0.08)$. MS was observed in only $7.3 \%$ of patients with the NCEP-ATPIII definition and $11.2 \%$ with the IDF criteria. Whatever the used definition, there was a significant association between MS presence and increased CIMT $(p<0.05)$ in univariate and multivariate model.

Conclusions: Non-HDL-C, TG/HDL ratio and apolipoprotein B levels, which are closely linked to lipid disorders associated to the MS, appear as stronger predictive markers than LDL-C for screening sub-clinical atherosclerosis in HIV+ populations. Achieving non-HDLC target defined by the NCEP-ATPIII guidelines appears of great importance to reduce CV complications in HIV+ patients.

Key words : apolipoprotein B; atherosclerosis; HIV infection; intima-media thickness; metabolic syndrome; non-HDL-cholesterol, TG/HDL ratio. Introduction 
The introduction of combined antiretroviral therapy (c-ART) has significantly increased the survival rates of HIV-positive $(\mathrm{HIV}+)$ patients and has improved their quality of life $^{1}$. However emergence of cardiovascular (CV) complications related to HIV infection per se and/or to c-ART has raised clinical and public health concerns ${ }^{2-5}$ given the increasing duration of exposure to c-ART. Several classical CV risk factors including age, gender, body mass index (BMI), blood pressure, increased total cholesterol (TC) levels or tobacco consumption have been previously recognized in HIV + patients $^{6}$. Surprisingly, there are contradictory reports on the association between low density lipoprotein cholesterol (LDL-C), the most recognized lipid risk factor in non-HIV populations ${ }^{7}$, and CIMT in HIV+ populations $^{8-11}$. Because classical risk factors do not account for all atherosclerosis risk in HIV+ patients, a search for non-classical could be of interest. Some of them could be directly related to HIV infection or its treatment such as duration of c-ART, time from HIV diagnosis, HIV plasma viral load or lipodystrophy ${ }^{12-15}$. Other ones including non-high density lipoprotein (HDL) cholesterol, Triglyceride (TG) to HDL ratio, apolipoprotein B (apoB), LDL size, inflammation or oxidative stress could be related to metabolic disorders such as metabolic syndrome (MS) and lipid triad (LT). LT defined as low HDL-C, high TG and small dense LDL presence ${ }^{16}$ represents the characteristic dyslipidemia of MS. In order to evaluate non classical CV risk factors, we studied firstly the relationship between CIMT and biological parameters (lipids, inflammation and oxidative stress markers); then the relationship between CIMT and metabolic cluster (MS, LT) presence.

\section{Patients and methods}

\section{1- Study design}

This ancillary study was performed on 232 HIV+ patients from the SUPRA (Surveillance of the Progression of Atherosclerosis) study sample extracted from the ANRS 
CO3 (Agence Nationale de Recherches sur le SIDA et les hépatites virales) Aquitaine cohort. In brief, $423 \mathrm{HIV}+$ patients were included consecutively between September and December 1999 in order to investigate the extent of atherosclerosis by measuring the CIMT and studying $\mathrm{CV}$ risk factors ${ }^{8}$. Blood samples were collected the day of CIMT measurement after an overnight fasting. A subgroup of 232 patients was selected on the basis of available aliquots frozen at $-80^{\circ} \mathrm{C}$ to perform complementary analysis including inflammation, oxidative stress parameters and LDL size determination. There was no significant difference between the characteristics of patients of this subgroup of 232 patients compared to the entire cohort of 423 patients.

\section{2- Initial study procedures}

CIMT measurement: The ultrasonographic scanning of carotid arteries was performed while the subjects were lying in the decubitus position. IMT of the left common carotid artery was measured by high resolution B-mode ultrasonography (ACUSON, Paris, France) on the far wall carotid arterial with a mechanical sector transducer of $7.5 \mathrm{MHz}$ frequency and a pulsed Doppler, as previously described ${ }^{8}$.

Lipodystrophy was categorized as peripheral fat accumulation, lipoatrophy and mixed syndrome on the basis of clinical examination and standardized questionnaire ${ }^{17}$.

Immuno-virological parameters: $\mathrm{CD}^{+}$cell count (flow cytometry) and plasma HIV-1 viral load (Chiron Quantiplex RNA HIV-1, Emeryville, CA, USA) were determined.

Biological parameters: glucose and insulin (Enzyme linked immunosorbent assay) were determined to calcul HOMA index with the formula ${ }^{18}$ : insulin $(\mu \mathrm{UI} / \mathrm{l}) \mathrm{x}$ glucose (mmol/l)/22.5. TG, TC and HDL-C concentrations were measured by enzymatic method. LDL-C was calculated with the Friedwald's formula for TG $<4.5 \mathrm{mmol} / \mathrm{l}$; non-HDL-C was 
defined as (TC - HDL-C). ApoA1 and apoB were measured by immunonephelemetric method.

\section{3- Complementary study procedures}

LDL size: The size of the predominant LDL subfraction was determined by plasma electrophoretic migration in non-denaturant polyacrylamide gradient gels (Spiragel 1.5 to $25 \%$, Lara-Spiral, France) as previously described ${ }^{19}$.

Inflammation parameters: High sensitive C-Reactive Protein (hs-CRP), albumin and prealbumin levels were determined using immuno-turbidimetric assay on a Olympus 2700 analyzer (Olympus, Rungis, France) ${ }^{20}$.

\section{Oxidative stress parameters:}

i) Total antioxidant capacity of the plasma (TAC) was measured using the Trolox equivalent antioxidant capacity with a colorimetric technique (Randox, Mauguio, France) adapted on an Olympus 2700 analyzer (Olympus, Rungis, France);

ii) Plasma concentration of advanced oxidation protein products (AOPP), considered as an index of protein oxidation, was measured by spectrophotometry (340 nm) using chloramine T and expressed as micromoles per liter of chloramine $\mathrm{T}$ equivalents ${ }^{21}$;

iii) Plasma malonyldialdehyde (MDA) levels, as a marker of lipid peroxidation were determined by spectrofluorometry ${ }^{22}$;

iv) Plasma concentration of advanced glycation end products (AGEs) was determined on diluted (water) plasma sample by fluorescence at $460 \mathrm{~nm}$ after excitation at $335 \mathrm{~nm}$ on a Vicktor apparatus (Wallac Turku Finland) ${ }^{23}$. Results were expressed in arbitrary units (AU); v) Measurement of anti MDA-modified LDL auto-antibodies (MDA-LDL Ab) was performed using an enzyme linked immunosorbent assay ${ }^{24}$. Briefly, antigen was prepared by incubation of isolated LDL for 3 hours at $37^{\circ} \mathrm{C}$ with MDA. Serum samples were assessed in duplicate at 
1:100 and 1:400 dilutions, anti-human IgG peroxidase-conjugated antibody (Biorad) was diluted at 1:2000. The peroxidase activity was developed with orthophenylenediamine and absorbance was measured at $450 \mathrm{~nm}$ after $8 \mathrm{~min}$ of incubation at room temperature. The difference between the absorbance of the sample and a blank in which PBS-Tween buffer was substituted for the sample dilution was calculated. Results were expressed in AUs.

\section{4- Metabolic cluster definition}

- MS was defined by the National Cholesterol Education Program guidelines Adult Treatment Panel III (NCEP-ATP III) criteria, i.e. if three or more of the following five risk determinants were present: fasting glucose $\geq 1.10 \mathrm{~g} / \mathrm{l}(6.1 \mathrm{mmol} / \mathrm{l})$; waist circumference $>102 \mathrm{~cm}$ for men, $>88 \mathrm{~cm}$ for women; $\mathrm{TG} \geq 1.5 \mathrm{~g} / \mathrm{l}(1.69 \mathrm{mmol} / \mathrm{l}) ; \mathrm{HDL}-\mathrm{C}<0.4 \mathrm{~g} / \mathrm{l}(1.04 \mathrm{mmol} / \mathrm{l})$ for men, $<0.5$

$\mathrm{g} / \mathrm{l}(1.29 \mathrm{mmol} / \mathrm{l})$ for women ; blood pressure $\geq 130 / 85 \mathrm{mmHg}^{25}$. In addition, patients treated by hypertensive medication were categorized as having high blood pressure, and patients receiving fibrate treatment were considered as having $\mathrm{TG} \geq 1.5 \mathrm{~g} / \mathrm{l}$.

- According to the International Diabetes Federations (IDF) criteria, MS was defined on the presence of an increased waist circumference: $\geq 94 \mathrm{~cm}$ for men, $\geq 80 \mathrm{~cm}$ for women, associated with two or more of the following criteria: fasting glucose $\geq 1.0 \mathrm{~g} / \mathrm{l}(5.6 \mathrm{mmol} / \mathrm{l})$ and/or medication; previously diagnosed type 2 diabetes; triglycerides $\geq 1.5 \mathrm{~g} / 1$ or specific treatment; HDL-C $<0.4 \mathrm{~g} / 1$ for men, $<0.5 \mathrm{~g} / \mathrm{l}$ for women or specific treatment; blood pressure $\geq 130 / 85$ and/or medication ${ }^{26}$.

- LT was defined as the combination of three lipid disorders that are TG levels $\geq 1.5 \mathrm{~g} / \mathrm{l}$, HDL$\mathrm{C}<0.4 \mathrm{~g} / 1$ for men, $<0.5 \mathrm{~g} / \mathrm{l}$ for women, and LDL size $<25.5 \mathrm{~nm}^{16}$.

\section{5- Statistical analysis}


Results are expressed as percentages for categorical variables, as mean \pm standard deviation (sd) for quantitative variables. Comparisons of markers values according to the presence of LT or MS were performed using a Student t-test. Correlations between continuous variables were calculated using the Spearman coefficient. Comparisons of CIMT values according to marker levels were done using a Student t-test and ANOVA when appropriate. Adjustment on age, gender and tobacco consumption was performed with multiple linear regression. Other comparisons between qualitative variables were performed with Chi-square test. All analyses were performed using SAS Software version 9.1 (SAS Institute, Cary, NC, USA).

\section{Results}

\section{1- Clinical and immuno-virological characteristics of patients}

In this sample of 232 patients, mean age was $41 \pm 9$ years, $75 \%$ were male, $70 \%$ were current smokers. Mean systolic/diastolic blood pressure was $121 \pm 12.3$ / 75 $\pm 9.4 \mathrm{mmHg}$. Only $3 \%$ of patients have blood pressure $\geq 130 / 85 \mathrm{mmHg}$. Mean BMI was $22 \pm 3.1 \mathrm{~kg} / \mathrm{m}^{2}$ and mean waist-to-hip ratio $0.9 \pm 0.08$. Eighty six patients $(37 \%)$ presented a fat distribution abnormality: $2 \%$ a fat accumulation alone, $16 \%$ a lipoatrophy alone and $20 \%$ a mixed syndrome. Eighty percent were treated with c-ART, $46 \%$ with a regimen including protease inhibitor (PI) and $31 \%$ with a non-nucleoside reverse transcriptase inhibitor (NNRTI). Mean duration of c-ART was $37 \pm 25.8$ months (NRTI: $37 \pm 25.7$ months, PI: $16 \pm 15.1$ months, NNRTI: $2 \pm 4$ months). Mean HIV-1 viral load was $2.9 \pm 1.1 \log _{10} \mathrm{cp} / \mathrm{ml}$ and mean $\mathrm{T}$ lymphocyte CD4+ count was $465 \pm 286 \mathrm{cell} / \mathrm{mm}^{3}$.

\section{2- Relationship between biological parameters and CIMT}


Increased TC, non-HDL-C, apoB levels and TG/HDL ratio were significantly associated with a $0.05 \mathrm{~mm}$ increase in CIMT when comparing the highest quartile against the lowest one in univariate analysis (Table 1). After adjustment on age, gender and tobacco consumption, these relationships disappeared but it remained a trend toward significant association between TG/HDL molar ratio $>1.5$ and CIMT $(\mathrm{p}=0.08)$. LDL size, that was negatively correlated with TG levels $\left(r=-0.37 \mathrm{p}<10^{-4}\right)$ and TG/HDL ratio $\left(r=-0.36 \mathrm{p}<10^{-4}\right)$ but not with insulin levels ( $\mathrm{p}=0.41)$ or with HOMA index $(\mathrm{p}=0.37)$, did not appear as a biological determinant of CIMT. There was also no significant difference of CIMT related to the presence of small dense LDL defined as LDL size $<25.5 \mathrm{~nm}(\mathrm{p}=0.17)$.

Interestingly, LDL-C recognized in the general population as the most common lipid risk factor, was not significantly associated with CIMT $(\mathrm{p}=0.09)$ in univariate analysis by contrast to non-HDL-C levels $\left(\mathrm{p}=9.10^{-3}\right)$. The correlation between apoB and LDL-C was lower $\left(\mathrm{r}=0.88, \mathrm{p}<10^{-4}\right)$ than with non HDL-C $\left(\mathrm{r}=0.94, \mathrm{p}<10^{-4}\right)$. In addition, there was also no statistical association between CIMT and recognized CV protective factors in the general population such as HDL-C $(\mathrm{p}=0.34)$ and apoA1 $(\mathrm{p}=0.63)$.

Inflammation assessed by hs-CRP level was not statistically related to CIMT $(p=0.11)$. In addition no parameter of oxidative stress was associated with CIMT (AOPP: $p=0.26$; MDA: $\mathrm{p}=0.49$; AGEs: $\mathrm{p}=0.30$; MDA-LDL Ab: $\mathrm{p}=0.71$; $\mathrm{TAC}: \mathrm{p}=0.27)$.

\section{3- Metabolic and biological clusters}

\section{- Metabolic syndrome}

Prevalence of the MS was 7.3\% ( $\mathrm{n}=17)$ using the NCEP-ATP III definition and $11.2 \%$ $(\mathrm{n}=26)$ with the IDF criteria.

The presence of MS was associated with a significant increase in CIMT compared to absence of MS, whatever the definition used, in univariate and multivariate analysis (Table 2). This 
increase of CIMT was of $0.10 \mathrm{~mm}$ for patients with MS defined by NCEP-ATP III criteria

$\left(0.66 \pm 0.16\right.$ vs $\left.0.56 \pm 0.10 \mathrm{~mm}, \mathrm{p}=1.510^{-3}\right)$ and of $0.08 \mathrm{~mm}(0.64 \pm 0.16$ vs $0.56 \pm 0.09 \mathrm{~mm}$, $\mathrm{p}=3.10^{-3}$ ) for patients with MS according to IDF criteria.

There was no significant difference in frequency of PI use between patients with or without MS: $52.9 \%$ vs $48.8 \%$ if the MS was defined by NCEP-ATP III and $46.1 \%$ vs $49.5 \%$ if the MS was defined by IDF. There was a trend towards an increased prevalence of lipodystrophy in patients with the NCEP-ATP III defined MS compared to those without (58.8\% vs 35.8\%, $\mathrm{p}=0.06)$ reaching significance with IDF definition $(69.2 \%$ vs $33.5 \%, \mathrm{p}<0.001)$.

Beyond hypertriglyceridemia and low HDL-C levels, patients with MS compared to those without had significant increase in non-HDL-C and apoB levels, whatever the definition used. The lipid profile of patients with the MS was also characterized by decreased apoA1 levels and LDL size when compared to patients without MS while TC and LDL-C were similar (Table 3). There was no difference in inflammation markers including hs-CRP, albumin and prealbumin levels according to the presence or absence of the MS (Table 3). As protein oxidation marker, AOPP levels were significantly increased in patients with the MS compared to those without. Because comparison of biological parameters between patients with or without MS defined by NCEP or IDF criteria was similar for all parameters, data are not shown for IDF definition.

\section{- Lipid Triad}

Mean CIMT was similar $(0.60 \pm 0.13$ vs $0.57 \pm 0.10 \mathrm{~mm}, \mathrm{p}=0.14)$ in presence and absence of the LT defined as the combination of TG $\geq 1.5 \mathrm{~g} / 1$, HDL-C $<0.4 \mathrm{~g} / 1$ for men, $<0.5$ $\mathrm{g} / \mathrm{l}$ for women, and LDL size $<25.5 \mathrm{~nm}$ (Table 2). 
Patients with the LT ( $n=43$, prevalence of 19\%) were statistically more prone to have lipodystrophy (58.1 vs $32.8 \%, \mathrm{p}<0.01)$ and to receive PI $(65.1$ vs $45.5 \%, \mathrm{p}<0.05)$ when compared to patients without the LT.

Beyond lipid disturbances included in the LT definition, TC, non-HDL-C and apoB levels were significantly higher while apoA1 levels were lower in patients with the LT compared to those without. Similarly to the MS, there was no significant difference in LDL-C levels with regard to the LT presence (Table 4). Interestingly, there was no statistical difference in insulin levels, HOMA levels or prevalence of insulin-resistance defined as HOMA index $>4$ in relation to the LT presence or absence (Table 4). Moreover, no association of the LT with inflammation markers including hs-CRP, albumin and prealbumin levels was observed (Table 4). Likewise to the MS, significant elevated AOPP levels were associated with the presence of the LT $\left(\mathrm{p}<10^{-4}\right)$.

\section{Discussion}

In this study, we demonstrated that non-HDL-C, apoB or TG/HDL ratio are stronger predictive factors of increased CIMT than LDL-C in HIV+ patients, in univariate analysis, while after adjustment on age, sex and smoking habits, TG/HDL ratio $>1.5$ appeared as an interesting determinant of subclinical atherosclerosis. These results were in agreement with previous data in the general population reporting a higher predictive value of non-HDL-C than LDL-C in CV risk assessment ${ }^{27}$. In addition, metabolic cluster disturbance such as MS presence was associated with increase in CIMT, while LT was not.

Non-HDL-C increase, closely linked to increased TG/HDL ratio, appears as a result of abnormal lipoprotein metabolism characterized by increased production of VLDL and/or delayed clearance of VLDL, as frequently observed in diabetes type II patients ${ }^{28}$ and in HIV+ patients $^{29-31}$. Classically, VLDL accumulation is associated to new lipid exchange pathways 
leading to decrease in LDL size and HDL-C levels ${ }^{32}$. This combination of elevated serum TG, decreased HDL-C and LDL size constitute the $\mathrm{LT}^{33}$, an atherogenic risk factor in the general population ${ }^{16}$. Surprisingly, the LT presence was not associated to increased CIMT in our HIV cohort, suggesting a worse role of VLDL per se. In addition, mechanism of VLDL accumulation in HIV+ patients appears more complex than in diabetes type II patients where insulin-resistance plays a central role ${ }^{34}$. Indeed, there was no association between the LT and HOMA index in the present study (See Table 4), by contrast with the frequent occurrence of LT in insulin resistance state in the general population ${ }^{33}$. This independence between dyslipidemia and insulin disorders, previously observed in some HIV+ patients ${ }^{31,35,36}$ could be related to recent evidence of a direct effect of decreased adiponectin level on VLDL clearance $^{37,38}$.

The significant relationship between apoB and CIMT underlined the atherogenicity of all apoB-containing lipoproteins (IDL, VLDL, LDL), but increased VLDL particles seems to represent the major atherogenic lipid factor in HIV+ patients. Indeed, no relationship was observed between LDL-C levels and CIMT, even in univariate analysis, while LDL-C was correlated with apoB. Although LDL-C was determined by the use of Friedwald's formula, it is unlikely that the relationship between LDL-C and CIMT has been skewed, as there were only nine patients (3.9\%) with TG levels $\geq 4.5 \mathrm{mmol} / \mathrm{l}$, whose measurements did not allow the LDL-C calculation. VLDL atherogenicity could be related to its ability to infiltrate the intimamedia space when endothelial permeability is altered, leading to their uptake by the macrophage via a VLDL receptor, thus accelerating the formation of foam cells ${ }^{39}$.

From a clinical point of view, non-HDL-C level or TG/HDL ratio determination appears of greatest interest to screen HIV+ patients with a proatherogenic profile but with a LDL-C in the reference range. The interest to determine non-HDL-C is the existing of specific 
goal defined by the NCEP-ATPIII guidelines as LDL-C target $+30 \mathrm{mg} / \mathrm{dl}(+0.77 \mathrm{mmol} / \mathrm{l})$ in the general population ${ }^{25}$. The ACTG/IDSA lipid guidelines mentioned the non-HDL-C level as a secondary therapeutic target after LDL-C for HIV+ patients with TG ranging from $2 \mathrm{~g} / \mathrm{l}$ to $5 \mathrm{~g} / \mathrm{l}(2.3 \text { to } 5.6 \mathrm{mmol} / \mathrm{l})^{40}$. In our study, mean LDL-C $(3.3 \pm 1.1 \mathrm{mmol} / \mathrm{l})$ was equal to the primary prevention cut-off of $130 \mathrm{mg} / \mathrm{dl}(3.3 \mathrm{mmol} / \mathrm{l})$ and was independent of the presence of MS or LT. By contrast non-HDL-C appears dependent to metabolic parameters and overwhelmed the threshold value of $4.1 \mathrm{mmol} / \mathrm{l}(160 \mathrm{mg} / \mathrm{dl})$ in case of MS or LT presence. Although an increase in non-HDL-C was statistically associated to increased CIMT in univariate analysis only (See Table 1), it appears necessary to reach the non-HDL-C goal after the LDL-C goal in HIV+ patients who are generally exposed to multiple CV risks and predisposed to increased atherosclerosis ${ }^{6,8-10,12}$. A particularity of dyslipidemia in HIV+ patients treated by c-ART is the combination of lipid disturbances related firstly to the HIV infection per se and secondly induced by c-ART. Management of this complex dyslipidemia appears as an important challenge for clinicians, as often, lipid lowering therapy alone does not allow to reach the lipid target ${ }^{36,41,42}$ and should be associated to diet and lifestyle modification and/or switching of some antiretroviral agents ${ }^{43}$. A specific disturbance that persists in about half of patients is a trend to low HDL-C levels and moderate hypertriglyceridemia. In this context, the determination of a TG/HDL cut-off associated to a significant sub-clinical atherosclerosis presence appears as a useful tool for clinicians. The TG/HDL molar ratio was previously reported as a marker of LDL size with a cut-off at 1.3 for identifying diabetic patients having small dense $\mathrm{LDL}^{44}$. In addition to a significant linear correlation between TG/HDL ratio and LDL size $\left(r=-0.36 \mathrm{p}<10^{-4}\right)$ observed in our study, a value of 1.5 was identified as the significant cut-off for distinguishing HIV+ patients having higher CIMT. Furthermore, other studies such as the DAD collaboration reported an 
independent effect of dyslipidemia on myocardial infarction in HIV+ patients underlining the need to analyse more deeply those lipid abnormalities ${ }^{45}$.

The MS is recognized as a clinical condition associated with an enhanced risk of CV diseases ${ }^{46}$. To identify MS, NCEP-ATP III criteria is the most frequently used classification, while a more recent definition was provided by the IDF, leading to some difference in MS prevalence ${ }^{47}$. This latter definition was reported to select more patients than NCEP which were characterized by less insulin-resistance and lower CIMT $^{48}$. In our study, prevalence of MS was indeed higher with IDF (11.2\%) than with NCEP-ATP III criteria (7.3\%) and HOMA index > 4 was more frequent when using NCEP-ATP III rather than IDF definition for MS (64.7\% and 53.8\% respectively). The statistical significant association between the MS presence and increase in the CIMT was similar whatever the definition used, in univariate and multivariate analysis (Table 2). This observation was in agreement with recent data reporting a significant association between increased common CIMT and MS presence, while internal CIMT was similar in patients with and without $\mathrm{MS}^{49}$, a result that could be due in part to the lesser variability of common CIMT measurement. In our study, CIMT was measured only on the left far wall carotid arterial in order to obtain more interpretable findings for all patients, but the bulb or the internal carotid was not explored. Controversial results were reported in HIV+ women, as no difference of CIMT was observed between patients with and without $\mathrm{MS}^{50}$. In our, study patients with MS were more likely to have lipodystophy compared to those without MS (58.8\% vs $35.8 \%$ and $69.2 \%$ vs $33.5 \%$ with NCEP-ATPIII and IDF definition, respectively), in line with the overlap of some abnormalities of lipodystophy such as visceral lipo-accumulation or insulin resistance with components of the MS diagnosis. However, the low rate of MS could hide some association as there was no difference in frequency of PI use between patients with or without MS (52.9\% 
vs $48.8 \%$ and $46.1 \%$ vs $49.5 \%$ with NCEP-ATPIII and IDF definition, respectively) by contrast to the relationship between PI exposure and MS previously reported in larger cohort $^{51}$, or in a women only cohort ${ }^{50}$. Nevertheless, the relative under-representation of MS in our rather young HIV+ cohort (41 \pm 9 years) compared to previous reports ${ }^{51-53}$ was in agreement with epidemiological data obtained in a large French cohort, mostly HIV-negative, reporting MS (NCEP-ATP III criteria) in $10.2 \%$ of men with a mean age of 48 years, dropping to $5 \%$ for subjects younger than 40 years $^{54}$. In the general population, MS is associated with inflammation and oxidative stress markers that contribute to the increased atherosclerosis risk ${ }^{55,56}$. In our study, presence of MS was not associated with inflammation markers including hs-CRP, albumin and prealbumin levels, in contrast to a previous report in HIV+ populations ${ }^{51}$. There was also no association of MS with oxidative stress marker, excepting an increase in AOPP levels. It should be underlined that this absence of relationship between MS and inflammation or oxidative stress parameters could be related to the low prevalence of MS in this cohort of limited size.

A main limitation of this study is its cross-sectional design. Further prospective studies could be conducted to determine the capacity of non-HDL-C, apoB, or TG/HDL ratio for predicting progression of CIMT and occurrence of cardiovascular events in larger cohort of HIV+ patients.

In conclusion, considering the stronger relationship between CIMT and non-HDL-C, apoB, or TG/HDL ratio than with LDL-C, and the higher risk of cardiovascular events in HIV+ population cumulating multiple cardiovascular risk factors ${ }^{9,57}$, reaching non HDL-C goal defined by the NCEP-ATP III and the ACTG/IDSA lipid guidelines appears necessary to 
manage $\mathrm{CV}$ risk beyond beneficial intervention on other modifiable factors such as tobacco consumption $^{58}$.

Financial support: "The Agence Nationale de Recherches sur le Sida et les hepatites virales" (ANRS, Paris, France) supports the ANRS CO3 Aquitaine Cohort. The SUPRA study was sponsored by the French Charity "Sidaction."

\section{References}

1. Palella FJ Jr, Baker RK, Moorman A et al. HIV Outpatient Study Investigators. Mortality in the highly active antiretroviral therapy era: changing causes of death and disease in the HIV outpatient study. J Acquir Immune Defic Syndr 2006; 43:27-34.

2. Currier JS, Taylor A, Boyd F et al. Coronary Heart Disease in HIV-Infected Individuals. J Acquir Immune Defic Syndr 2003; 33:506-512.

3. Saves M, Chene G, Ducimetiere P, et al. Risk factors for coronary heart disease in patients treated for human immunodeficiency virus infection compared with the general population. Clin Infect Dis 2003; 37:292-298.

4. Law M, Friis-Moller N, Weber R et al. Modelling the 3-year risk of myocardial infarction among participants in the Data Collection on Adverse Events of Anti-HIV Drugs (DAD) study. HIV Med 2003; 4:1-10.

5. Glass TR, Ungsedhapand C, Wolbers M et al. Swiss HIV Cohort Study. Prevalence of risk factors for cardiovascular disease in HIV-infected patients over time: the Swiss HIV Cohort Study. HIV Med 2006; 7:404-10.

6. Friis-Moller N, Weber R, Reiss $\mathrm{P}$ et al. Cardiovascular disease risk factors in HIV patients--association with antiretroviral therapy. Results from the DAD study. AIDS $2003 ; 17: 1179-93$. 
7. Eisenberg DA. Cholesterol lowering in the management of coronary artery disease: the clinical implications of recent trials. Am J Med 1998;104:2S-5S.

8. Mercie P, Thiebaut R, Lavignolle $\mathrm{V}$ et al. Evaluation of cardiovascular risk factors in HIV-1 infected patients using carotid intima-media thickness measurement. Ann Med $2002 ; 34: 55-63$.

9. Hsue PY, Lo JC, Franklin A et al. Progression of atherosclerosis as assessed by carotid intima-media thickness in patients with HIV infection. Circulation 2004; 109:1603-8.

10. Lebech AM, Wiinberg N, Kristoffersen US et al. Carotid intima-media thickness in HIV patients treated with antiretroviral therapy. Clin Physiol Funct Imaging 2007; 27:173-9.

11. Currier JS, Kendall MA, Henry Wk et al. Progression of carotid artery intima-media thickening in HIV-infected and uninfected adults. AIDS 2007; 21:1137-45.

12. Friis-Moller N, Sabin CA Weber R et al. Combination antiretroviral therapy and the risk of myocardial infarction. N Engl J Med 2003; 349:1993-2003.

13. Mary-Krause M, Cotte L, Simon A, Partisani M, Costagliola D- The Clinical Epidemiology Group from the French Hospital Database. Increased risk of myocardial infarction with duration of protease inhibitor therapy in HIV-infected men. AIDS 2003; 17: 2479-2486.

14. Jerico C, Knobel H, Calvo $\mathrm{N}$ et al. Subclinical carotid atherosclerosis in HIV-infected patients: role of combination antiretroviral therapy. Stroke 2006; 37:812-7.

15. Coll B, Parra S, Alonso-Villaverde C et al. HIV-infected patients with lipodystrophy have higher rates of carotid atherosclerosis: the role of monocyte chemoattractant protein-1. Cytokine 2006; 34:51-5. doi:10.1016/j.cyto.2006.03.013. 
16. Austin MA, King MC, Vranizan KM, Krauss RM. Atherogenic lipoprotein phenotype. A proposed genetic marker for coronary heart disease risk. Circulation 1990; 82:495506.

17. Thiebaut R, Daucourt V, Mercie P et al, Groupe d'Epidemiologie Clinique du Sida en Aquitaine (GESCA). Lipodystrophy, metabolic disorders, and human imunodeficiency virus infection: Aquitaine Cohort, France, 1999. Clin Infect Dis 2000; 31:1482-7.

18. Matthews DR, Hosker JP, Rudenski AS et al. Homeostasis model assessment: insulin resistance and beta-cell function from fasting plasma glucose and insulin concentrations in man. Diabetologia $1985 ; 28: 412-419$.

19. Badiou S, Merle De Boever C, Dupuy AM, Baillat V, Cristol JP, Reynes J. Decrease in LDL size in HIV-positive adults before and after lopinavir/ritonavir-containing regimen: an index of atherogenicity? Atherosclerosis 2003; 168:10713.doi:10.1016/S0021-9150(03)00058-3.

20. Dupuy AM, Badiou S, Descomps B, Cristol JP. Immunoturbidimetric determination of C-reactive protein (CRP) and high-sensitivity CRP on heparin plasma. Comparison with serum determination. Clin Chem Lab Med 2003; 41:948-9.

21. Witko-Sarsat V, Friedlander M, Nguyen Khoa T et al. Advanced oxidation protein products as novel mediators of inflammation and monocyte activation in chronic renal failure. J Immunol 1998; 161:2524-32.

22. Yaggi K. A simple fluorometric assay for lipoperoxide in blood plasma. Biochem Med $1976 ; 15: 212-216$.

23. Schwedler SB, Metzger T, Schinzel R, Wanner C. Advanced glycation end products and mortality in hemodialysis patients. Kidney Int 2002; 62:301-10. 
24. Maggi E, Chiesa R, Melissano G et al. LDL oxidation in patients with severe carotid atherosclerosis. A study of in vitro and in vivo oxidation markers. Arterioscler Thromb 1994; 14:1892-1899.

25. National Cholesterol Education Program (NCEP) Expert Panel on Detection, Evaluation, and Treatment of High Blood Cholesterol in Adults (Adult Treatment Panel III).Third Report of the National Cholesterol Education Program (NCEP) Expert Panel on Detection, Evaluation, and Treatment of High Blood Cholesterol in Adults (Adult Treatment Panel III) final report. Circulation 2002; 106:3143-3421.

26. Alberti KG, Zimmet P Shwa J. The metabolic syndrome-a new worldwide definition. Lancet 2005; 366:1059-1062. doi:10.1016/S0140-6736(05)67402-8.

27. Cui Y, Blumenthal RS, Flaws JA et al. Non-high-density lipoprotein cholesterol level as a predictor of cardiovascular disease mortality. Arch Intern Med 2001;161:14131419.

28. Krauss RM. Lipids and lipoproteins in patients with type 2 diabetes. Diabetes Care $2004 ; 27: 1496-504$.

29. Schmitz M, Michl GM Walli R et al. Alterations of apolipoprotein B metabolism in HIV-infected patients with antiretroviral combination therapy. J Acquir Immune Defic Syndr 2001; $26: 225-35$.

30. Reeds DN, Mittendorfer B, Patterson BW, Powderly WG, Yarasheski KE, Klein S. Alterations in lipid kinetics in men with HIV-dyslipidemia. Am J Physiol 2003; 285: E490-E497.

31. Carpentier A, Patterson BW, Uffelman KD, Salit I, Lewis GF. Mechanism of highly active anti-retroviral therapy-induced hyperlipidemia in HIV-infected individuals. Atherosclerosis 2005; 178:165-72. doi:10.1016/j.atherosclerosis.2004.07.035. 
32. Packard CJ, Sheperd J. Lipoprotein Heterogeneity and Apolipoprotein B Metabolism. Arterioscler Thromb Vasc Biol 1997; 17:3542-56.

33. Verges BL. Dyslipidaemia in diabetes mellitus. Review of the main lipoprotein abnormalities and their consequences on the development of atherogenesis. Diabetes Metab 1999; 25:32-40.

34. Avramoglu RK, Basciano H, Adeli K. Lipid and lipoprotein dysregulation in insulin resistant states. Clin Chim Acta 2006; 368:1-19.

35. Swanson B, Keithley JK, Zeller JM, Sha BE. Lack of association between dyslipidemia and insulin resistance in HIV-infected persons treated with highly active antiretroviral therapy. Nutrition 2004; 20:1022-5. doi:10.1016/j.nut.2004.08.013

36. Badiou S, Merle De Boever C, Dupuy AM, Baillat V, Cristol JP, Reynes J. Fenofibrate improves the atherogenic lipid profile and enhances LDL resistance to oxidation in HIV-positive adults. Atherosclerosis 2004; 172:273-9. doi:10.1016/j.atherosclerosis.2003.10.006.

37. Das S, Shahmanesh M, Stolinski M et al. In treatment-naive and antiretroviral-treated subjects with HIV, reduced plasma adiponectin is associated with a reduced fractional clearance rate of VLDL, IDL and LDL apolipoprotein B-100. Diabetologia 2006; 49:538-42.

38. Falasca K, Manigrasso MR, Racciatti D et al. Associations between Hypertriglyceridemia and Serum Ghrelin, Adiponectin, and IL-18 Levels in HIVinfected Patients. Ann Clin Lab Sci 2006; 36:59-66.

39. Eck MV, Oost J, Goudriaan JR et al. Role of the macrophage very-low-density lipoprotein receptor in atherosclerotic lesion development. Atherosclerosis 2005; 183:230-7. doi:10.1016/j.atherosclerosis.2005.03.045. 
40. Dubé MP, Stein JH, Aberg JA et al, Adult AIDS Clinical Trials Group Cardiovascular Subcommittee; HIV Medical Association of the Infectious Disease Society of America. Guidelines for the evaluation and management of dyslipidemia in human immunodeficiency virus (HIV)-infected adults receiving antiretroviral therapy: recommendations of the HIV Medical Association of the Infectious Disease Society of America and the Adult AIDS Clinical Trials Group. Clin Infect Dis 2003; 37:613-27.

41. Visnegarwala F, Maldonado M, Sajja P et al. Lipid lowering effects of statins and fibrates in the management of HIV dyslipidemias associated with antiretroviral therapy in HIV clinical practice. Journal of Infection 2004; 49:283-290. doi:10.1016/j.jinf.2003.09.006.

42. Aberg JA, Zackin RA, Brobst SW et al. ACTG 5087 Study Team. A randomized trial of the efficacy and safety of fenofibrate versus pravastatin in HIV-infected subjects with lipid abnormalities: AIDS Clinical Trials GroupStudy 5087. AIDS Res Hum Retroviruses 2005; 21:757-67.

43. Oh J, Hegele RA. HIV-associated dyslipidaemia: pathogenesis and treatment. Lancet Infect Dis 2007; 7:787-96. doi:10.1016/S1473-3099(07)70287-6

44. Boizel R, Benhamou PY, Lardy B, Laporte F, Foulon T, Halimi S. Ratio of triglycerides to HDL cholesterol is an indicator of LDL particle size in patients with type 2 diabetes and normal HDL cholesterol levels. Diabetes Care. 2000;23:1679-85.

45. DAD Study Group, Friis-Møller N, Reiss P, Sabin CA et al. Class of antiretroviral drugs and the risk of myocardial infarction. N Engl J Med. 2007;356:1723-35.

46. Gami AS, Witt BJ, Howard DE et al. Metabolic syndrome and risk of incident cardiovascular events and death: a systematic review and meta-analysis of longitudinal studies. J Am Coll Cardiol 2007; 49:403-14. doi:10.1016/j.jacc.2006.09.032. 
47. Saely $\mathrm{CH}$, Rein P, Drexel H. The metabolic syndrome and risk of cardiovascular disease and diabetes: experiences with the new diagnostic criteria from the international diabetes Federation. Horm Metab Res 2007; 39:642-50.

48. Sandhofer A, Iglseder B, Paulweber B, Ebenbichler CF, Patsch JR. Comparison of different definitions of the metabolic syndrome. Eur J Clin Invest 2007; 37:109-16.

49. Mangili A, Jacobson DL, Gerrior J, Polak JF, Gorbach SL, Wanke CA. Metabolic syndrome and subclinical atherosclerosis in patients infected with HIV. Clin Infect Dis 2007;44:1368-74.

50. Johnsen S, Dolan SE, Fitch KV et al .Carotid intimal medial thickness in human immunodeficiency virus-infected women: effects of protease inhibitor use, cardiac risk factors, and the metabolic syndrome. J Clin Endocrinol Metab 2006;91:4916-24

51. Samaras K, Wand H, Law M, Emery S, Cooper D, Carr A. Prevalence of metabolic syndrome in HIV-infected patients receiving highly active antiretroviral therapy using International Diabetes Foundation and Adult Treatment Panel III criteria: associations with insulin resistance, disturbed body fat compartmentalization, elevated C-reactive peptide, and hypoadiponectinemia. Diabetes Care 2007; 30:113-9.

52. Jerico C, Knobel H, Montero $M$ et al. Metabolic syndrome among HIV-infected patients: prevalence, characteristics, and related factors. Diabetes Care 2005; 28:1327.

53. Jacobson DL, Tang AM, Spiegelman D, et al. Incidence of metabolic syndrome in a cohort of HIV-infected adults and prevalence relative to the US population (National Health and Nutrition Examination Survey). J Acquir Immune Defic Syndr 2006, 43:458-66. 
54. Pannier B, Thomas F, Eschwege E et al. Cardiovascular risk markers associated with the metabolic syndrome in a large French population: the "SYMFONIE" study. Diabetes Metab 2006; 32:467-74. doi:10.1016/S1262-3636(07)70305-1.

55. Rutter MK, Meigs JB, Sullivan LM, D'Agostino RB Sr, Wilson PW. C-reactive protein, the metabolic syndrome, and prediction of cardiovascular events in the Framingham Offspring Study. Circulation 2004; 110:380-5.

56. Hansel B, Giral P, Nobecourt E et al. Metabolic syndrome is associated with elevated oxidative stress and dysfunctional dense high-density lipoprotein particles displaying impaired antioxidative activity. J Clin Endocrinol Metab 2004; 89:4963-71.

57. Mercie P, Thiebaut R, Aurillac-Lavignolle V et al - Groupe d'Epidemiologie Clinique du Sida en Aquitaine (GECSA). Carotid intima-media thickness is slightly increased over time in HIV-1-infected patients. HIV Med 2005; 6:380-7.

58. Thiebaut R, Aurillac-Lavignolle V, Bonnet F et al - Groupe d'Epidemiologie Clinique du Sida en Aquitaine (GECSA). Change in atherosclerosis progression in HIVinfected patients: ANRS Aquitaine Cohort, 1999-2004. AIDS 2005; 19:729-31. 
Table 1: Relationship between lipid parameters and carotid intima-media thickness (CIMT) (mean \pm sd)

\begin{tabular}{|c|c|c|c|c|}
\hline Parameters & Quartile & CIMT (mm) & $\mathrm{p}^{*}$ & $\mathrm{p} \#$ \\
\hline $\begin{array}{l}\text { LDL-C } \\
(\mathrm{mmol} / \mathrm{l})\end{array}$ & $\begin{array}{l}{[0.50-2.59]} \\
{[2.60-3.29]} \\
{[3.30-3.89]} \\
{[3.90-6.40]}\end{array}$ & $\begin{array}{l}0.55 \pm 0.07 \\
0.55 \pm 0.10 \\
0.58 \pm 0.12 \\
0.59 \pm 0.11\end{array}$ & 0.09 & 0.66 \\
\hline $\begin{array}{l}\mathrm{TC} \\
(\mathrm{mmol} / \mathrm{l})\end{array}$ & $\begin{array}{l}{[2.20-4.49]} \\
{[4.50-5.39]} \\
{[5.40-6.30]} \\
{[6.31-9.20]}\end{array}$ & $\begin{array}{l}0.55 \pm 0.07 \\
0.55 \pm 0.07 \\
0.58 \pm 0.13 \\
0.60 \pm 0.12\end{array}$ & $9.10^{-3}$ & 0.15 \\
\hline $\begin{array}{l}\text { Non-HDL-C } \\
(\mathrm{mmol} / \mathrm{l})\end{array}$ & $\begin{array}{l}{[1.20-3.29]} \\
{[3.30-4.09]} \\
{[4.10-5.09]} \\
{[5.10-7.80]}\end{array}$ & $\begin{array}{l}0.55 \pm 0.06 \\
0.55 \pm 0.07 \\
0.58 \pm 0.13 \\
0.60 \pm 0.12\end{array}$ & $9.10^{-3}$ & 0.41 \\
\hline $\begin{array}{l}\text { ApoB } \\
(\mathrm{g} / \mathrm{l})\end{array}$ & $\begin{array}{l}{[0.37-0.83]} \\
{[0.84-1.02]} \\
{[1.03-1.27]} \\
{[1.28-1.84]}\end{array}$ & $\begin{array}{l}0.55 \pm 0.06 \\
0.55 \pm 0.08 \\
0.59 \pm 0.12 \\
0.60 \pm 0.13\end{array}$ & $8.10^{-3}$ & 0.25 \\
\hline TG/HDL & $\begin{array}{l}{[0.20-0.69]} \\
{[0.70-1.40]} \\
{[1.41-2.50]} \\
{[2.51-20.0]}\end{array}$ & $\begin{array}{l}0.54 \pm 0.06 \\
0.56 \pm 0.08 \\
0.59 \pm 0.13 \\
0.58 \pm 0.12\end{array}$ & 0.02 & 0.41 \\
\hline TG/HDL & $\begin{array}{l}\leq 1.5 \\
>1.5\end{array}$ & $\begin{array}{l}0.55 \pm 0.08 \\
0.59 \pm 0.12\end{array}$ & $4.10^{-3}$ & 0.08 \\
\hline
\end{tabular}

* Comparison of the first versus the fourth quartile

\# Adjusted $\mathrm{p}$ values for age, gender and tobacco consumption. 
Table 2: Relationship between metabolic cluster and carotid intima-media thickness

(CIMT) (mean \pm sd)

\begin{tabular}{llllcc} 
& & $\mathrm{N}$ & CIMT $(\mathrm{mm})$ & $\mathrm{p}$ value & $\mathrm{p}^{\#}$ \\
\hline Metabolic syndrome & Yes & 17 & $0.66 \pm 0.16$ & $\mathbf{0 . 0 3}$ & $\mathbf{1 . 5}^{\mathbf{3}}$ \\
(NCEP-ATP III criteria) & No & 215 & $0.56 \pm 0.10$ & & \\
Metabolic syndrome & Yes & 26 & $0.64 \pm 0.16$ & $\mathbf{0 . 0 2}$ & $\mathbf{3 . 1 0 ^ { - 3 }}$ \\
(IDF criteria) & No & 206 & $0.56 \pm 0.09$ & & \\
Lipid Triad & Yes & 43 & $0.60 \pm 0.13$ & 0.14 & 0.36 \\
& No & 189 & $0.57 \pm 0.10$ & & \\
\hline
\end{tabular}

\# Adjusted $\mathrm{p}$ values for age, gender and tobacco consumption. 
Table 3: Relationship between biological parameters and metabolic syndrome (MS) presence defined by NCEP-ATP III criteria.

\begin{tabular}{|c|c|c|c|}
\hline & \multirow[b]{2}{*}{$\begin{array}{l}\text { Whole group } \\
\qquad(\mathrm{n}=232)\end{array}$} & \multicolumn{2}{|c|}{ Metabolic syndrome } \\
\hline & & $\begin{array}{c}\text { Yes } \\
(n=17)\end{array}$ & $\begin{array}{c}\text { No } \\
(n=215)\end{array}$ \\
\hline $\mathrm{TG}(\mathrm{mmol} / \mathrm{l}) \S$ & $2.0 \pm 1.5$ & $2.9 \pm 0.8 * *$ & $1.9 \pm 1.6$ \\
\hline HDL-C $(\mathrm{mmol} / \mathrm{l}) \S$ & $1.2 \pm 0.5$ & $0.9 \pm 0.2 * *$ & $1.3 \pm 0.5$ \\
\hline $\mathrm{TC}(\mathrm{mmol} / \mathrm{l})$ & $5.4 \pm 1.3$ & $5.8 \pm 1.1$ & $5.4 \pm 1.3$ \\
\hline Non-HDL C (mmol/1) & $4.2 \pm 1.3$ & $4.9 \pm 1.0^{*}$ & $4.1 \pm 1.3$ \\
\hline LDL-C (mmol/l) & $3.3 \pm 1.1$ & $3.6 \pm 1.0$ & $3.3 \pm 1.1$ \\
\hline LDL size (nm) & $25.52 \pm 0.50$ & $25.16 \pm 0.42 *$ & $25.55 \pm 0.50$ \\
\hline ApoB (g/l) & $1.0 \pm 0.3$ & $1.2 \pm 0.3 *$ & $1.0 \pm 0.3$ \\
\hline ApoA (g/l) & $1.3 \pm 0.3$ & $1.2 \pm 0.2^{*}$ & $1.4 \pm 0.3$ \\
\hline Insuline (UI/l) & $16.6 \pm 15.1$ & $32.5 \pm 25.2 *$ & $15.3 \pm 13.3$ \\
\hline HOMA index & $4.0 \pm 4.8$ & $9.3 \pm 9.9^{*}$ & $3.6 \pm 3.9$ \\
\hline HOMA > $4(\%)$ & 24.1 & $64.7^{* *}$ & 20.9 \\
\hline Hs-CRP (mg/l) & $4.9 \pm 8.0$ & $4.5 \pm 6.7$ & $4.9 \pm 8.1$ \\
\hline Albumin (g/l) & $45 \pm 5.6$ & $44.4 \pm 5.4$ & $45 \pm 5.7$ \\
\hline Prealbumin (g/l) & $0.22 \pm 0.07$ & $0.23 \pm 0.05$ & $0.22 \pm 0.07$ \\
\hline AOPP $(\mu \mathrm{mol} / 1)$ & $36.3 \pm 20.9$ & $54.3 \pm 20.8^{* *}$ & $34.8 \pm 20.2$ \\
\hline MDA (mmol/l) & $0.74 \pm 0.30$ & $0.63 \pm 0.18^{*}$ & $0.75 \pm 0.31$ \\
\hline AGEs (AU) & $13628 \pm 3217$ & $13427 \pm 2232$ & $13644 \pm 3286$ \\
\hline MDA-LDL Ab (AU) & $1556 \pm 1257$ & $1197 \pm 680$ & $1582 \pm 1287$ \\
\hline TAC (mmol/l) & $1.60 \pm 0.14$ & $1.58 \pm 0.11$ & $1.60 \pm 0.15$ \\
\hline
\end{tabular}

*, $<<0.05$ comparison of patient with MS versus without MS

**, $\mathrm{p}<0.001$ comparison of patient with MS versus without MS

$\S$ components of MS definition. 
Whole group

$(n=232)$

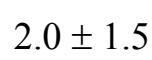

$1.2 \pm 0.5$

$25.52 \pm 0.50$

$5.4 \pm 1.3$

$3.3 \pm 1.1$

$4.2 \pm 1.3$

$1.0 \pm 0.3$

$1.3 \pm 0.3$

$18.0 \pm 27.0$

$4.0 \pm 4.8$

24.1

$5.4 \pm 10.4$

$45 \pm 5.6$

$0.22 \pm 0.07$

Prealbumin (g/l)

AOPP $(\mu \mathrm{mol} / \mathrm{l})$

MDA (mmol/l)

AGEs (AU)

MDA-LDL Ab (AU)

TAC (mmol/l)
$36.3 \pm 20.9$

$0.74 \pm 0.30$

$13628 \pm 3217$

$1556 \pm 1257$

$1.60 \pm 0.14$
$3.7 \pm 2.1^{* *}$

$0.8 \pm 0.1^{* *}$

$25.01 \pm 0.34 * *$

$6.0 \pm 1.5^{*}$

$3.5 \pm 1.3$

$5.0 \pm 1.4^{* *}$

$1.2 \pm 0.3 * *$

$1.1 \pm 0.2 * *$

$18.9 \pm 16.0$

$4.4 \pm 4.6$

30.2

$4.8 \pm 6.7$

$46 \pm 3.8$

$0.21 \pm 0.06$

$54.8 \pm 17.9^{* *}$

$0.79 \pm 0.3$

$14109 \pm 3035$

$1526 \pm 1545$

$1.63 \pm 0.11$
$1.6 \pm 1.0$

$1.3 \pm 0.5$

$25.64 \pm 0.46$

$5.3 \pm 1.2$

$3.3 \pm 1.1$

$4.0 \pm 1.2$

$1.0 \pm 0.3$

$1.4 \pm 0.3$

$17.8 \pm 28.9$

$3.9 \pm 4.8$

22.7

$5.5 \pm 11.1$

$45 \pm 5.9$

$0.23 \pm 0.07$

$33.1 \pm 19.7$

$0.73 \pm 0.3$

$13519 \pm 3255$

$1562 \pm 1188$

$1.60 \pm 0.15$

*, $\mathrm{p}<0.05$ comparison of patient with LT versus without LT

**, $\mathrm{p}<0.001$ comparison of patient with LT versus without LT

$\S$ components of LT definition. 